Check for updates

Cite this: RSC Adv., 2017, 7, 45521

Received 20th July 2017

Accepted 18th September 2017

DOI: 10.1039/c7ra08000j

rsc.li/rsc-advances

\section{Highly effective and reusable sulfonated pentablock copolymer nanocomposites for water purification applications $\dagger$}

\author{
S. Filice, ${ }^{\text {ab }}$ D. D'Angelo, (D) *a A. Scarangella, (D) f $^{\mathrm{c}}$ D. lannazzo, ${ }^{d}$ G. Compagnini ${ }^{\mathrm{b}}$ \\ and S. Scalese (D) *a
}

Nanocomposite membranes based on the use of a sulfonated pentablock copolymer (s-PBC) were prepared and investigated for the first time for water purification applications. The s-PBC is a thermoplastic elastomer with discrete sequences of ionic (sulfonated) and non-ionic (unsulfonated) blocks. Titania particles and graphene oxide (GO) were dispersed in the polymeric matrix and nanocomposite membranes (named s- $\mathrm{PBC}-\mathrm{TiO}_{2}$ and $\mathrm{s}-\mathrm{PBC}-\mathrm{GO}$, respectively) were prepared by drop casting. The chemical, structural and morphological properties of the nanocomposite membranes were characterized by scanning electron microscopy (SEM), Raman spectroscopy, X-ray diffraction (XRD) and thermogravimetric analysis (TGA). The adsorption properties and the photocatalytic activity of such nanocomposite membranes were investigated by analysing the removal of dyes from water solutions and the degradation of methylene blue (MB) and methyl orange (MO) under UV-visible light irradiation. The role played by the direct interaction of the polymer with the contaminant is also considered. Both the $\mathrm{s}-\mathrm{PBC}-\mathrm{GO}$ and $\mathrm{s}-\mathrm{PBC}-\mathrm{TiO}_{2}$ nanocomposites show high efficiency in dyes adsorption and photocatalytic degradation. All the nanocomposites investigated in the present study are able to degrade more than the $90 \%$ of the initial MB concentration either in dark or under irradiation. The introduction of the fillers in S-PBC favors a fast formation of $M B$ aggregates. $M O$ dye removal from water is efficiently achieved by s-PBC-GO and s-PBC- $\mathrm{TiO}_{2}$. In particular, s-PBC-GO is a safer material to be used for MO removal with respect to $\mathrm{s}-\mathrm{PBC}-\mathrm{TiO}_{2}$, since in the first case no formation of aromatic intermediate compounds is observed under UV-visible light irradiation.

\section{Introduction}

Nowadays, the environmental sustainability of water and energy supply is considered one of the most critical world challenges. The use of polymeric membranes can help to face up to these issues, for example in desalination processes involving reverse osmosis (RO), nanofiltration, forward osmosis (FO) ${ }^{\mathbf{1}}$ and can be also crucial to power generation applications (fuel cells, ${ }^{2}$ microbial fuel cells, ${ }^{3}$ photoelectrical solar cells ${ }^{4}$ ) and the realization of actuators. ${ }^{5}$ Membranes can be suitably modified in order to improve water and salt transport and, to this aim,

${ }^{a}$ CNR-IMM, Ottava Strada n.5, I-95121 Catania, Italy.E-mail: daniele.dangelo@imm. cnr.it; silvia.scalese@imm.cnr.it

${ }^{b}$ Dipartimento di Scienze Chimiche, Università di Catania, viale A. Doria 6, I-95125 Catania, Italy

${ }^{c}$ CNR-IMM, Via Santa Sofia 64, I-95123 Catania, Italy

${ }^{d}$ Dipartimento di Ingegneria Elettronica, Chimica e Ingegneria Industriale, Università degli Studi di Messina, Contrada di Dio, I-98166, Messina, Italy

$\dagger$ Electronic supplementary information (ESI) available. See DOI: 10.1039/c7ra08000j

+ Present address: CNRS, LAPLACE (Laboratoire Plasma et Conversion d'Energie), 118 Route de Narbonne, F-31062 Toulouse Cedex 9, France. sulfonated polymers are being explored as RO and FO membrane material. Actually, one of the main polymers used in the field of water purification and desalination is polyamide. Anyway, its performance highly declines due to oxidative degradation induced by chlorine-based chemicals present in water. As a consequence, more robust and durable membranes (i.e. resistant to oxidation by chemicals, such as the chlorinebased disinfectants used in water treatment, highly $\mathrm{pH}$ tolerant, and more resistant to fouling) but at the same time characterized by high flux and high salt rejection are needed. One approach is choosing polymers with robust, stable backbones but these are often rather hydrophobic (i.e., polysulfone, polystyrene, etc.) and therefore are not sufficiently permeable to water. A way to overcome this problem is adding charged groups (i.e., carboxylate or sulfonate groups) to the hydrophobic polymer resulting in a higher hydrophilicity and water permeability.

The addition of sulfonated groups to a hydrophobic polymer allows to confer a certain degree of hydrophilicity on $\mathrm{it}^{6}$ and, therefore, to tune and optimize the water flux/salt rejection trade-off. In addition, sulfonated membranes may offer other advantages over traditional polyamide-based thin-film composite membranes because they are resistant against 
degradation by the chlorine-containing disinfectants widely used in water treatment processes, ${ }^{7}$ they are $\mathrm{pH}$ tolerant, more resistant against fouling than currently used materials ${ }^{8}$ and to chemical reactions in a contaminated water due to the absence of ammine groups. However, a high degree of sulfonation can affect the mechanical stability of the polymeric membrane, since it can become hydrosoluble. A possible way to obtain high degree of sulfonation without weakening the mechanical resistance is given by the use of block copolymer architectures. ${ }^{9}$ The advantages of these polymers are mainly the low cost, the good processability, ease of functionalization, and the possibility to combine different properties owned by the hydrophobic and hydrophilic domains. ${ }^{9}$ The arrangement of the microdomains and the morphology depends on the properties of the blocks and vary with the degree of sulfonation, affecting the final thermal, mechanical, and transport behaviour of the membranes. Sulfonated poly(arylene ether sulfones) have been studied as potential desalination membranes. ${ }^{10}$ High degrees of sulfonation can lead to excessive swelling decreasing the polymer mechanical strength. Both crosslinking and block copolymer architectures restrict water uptake preventing highly sulfonated polymers from dissolving in water.

Recently, Nexar ${ }^{\mathrm{TM}}$, a sulfonated pentablock copolymer (sPBC), commercialized by Kraton Performance Polymers Inc. (Houston, TX), has been investigated in desalination applications. ${ }^{10}$ Fig. 1 shows the sequence of the s-PBC: tert-butyl styrene, hydrogenated isoprene, sulfonated styrene : styrene, hydrogenated isoprene, tert-butyl styrene (tBS-HI-sS : S-HI$t \mathrm{BS})$. The tert-butyl styrene end blocks do not undergo sulfonation since the tert-butyl group and the polymer backbone protect, respectively, the para and ortho positions of the phenyl ring. Additional toughness is provided to the copolymer by the hydrogenated isoprene block. The molecularly designed Nexar ${ }^{\mathrm{TM}}$ structure results in many advantages: unlike sulfonated poly(styrene- $b$-hydrogenated butadiene- $b$-styrene) or SEBS materials, in this new polymeric architecture the sulfonation is limited to the middle block, resulting in a polymer with controlled swelling and good mechanical properties in the hydrated state. ${ }^{10}$ It can achieve a high degree of sulfonation without a significant loss of mechanical stability. ${ }^{\mathbf{8 , 1 0 - 1 3}}$ Secondly, the degree of sulfonation of the copolymer can be easily tailored for various applications. In this new architecture, the tert-butyl group and the polymer backbone protect the favourable para and ortho positions of the phenyl avoiding sulfonation of styrene end blocks. The hydrogenated isoprene block gives the copolymer additional toughness. On the contrary, in SEBs

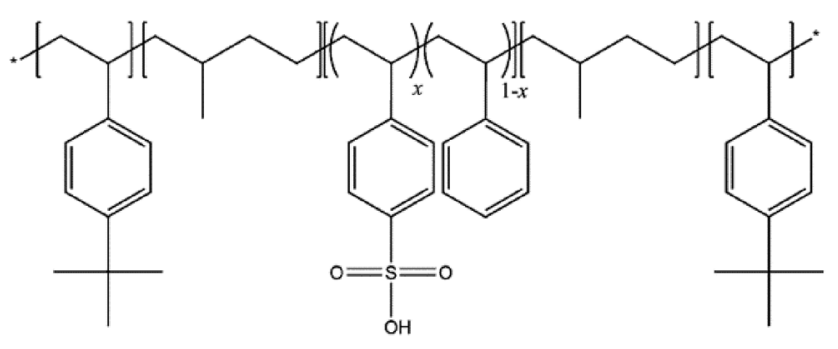

Fig. 1 Scheme of the NexarTM polymer. architecture the sulfonation of the styrene end blocks is uncontrollable leading to swelling and, thus, poor mechanical properties when hydrated. Thirdly, the merging of the middle sulfonated styrene block to form a continuous water transport passageway during formation of the film serves to further enhance the water permeability of the membrane..$^{\mathbf{8 1 2}, 13}$

Within all the advantages of using polymeric membranes for water purification, the incorporation of nano-sized materials within a polymeric matrix could produce synergistic effects. The removal of environmental pollutants through nano-sized inorganic semiconductors has aroused lively interest in the last few decades. ${ }^{14}$ In particular, titanium-based photocatalysis has been the subject of several studies in the field of self-cleaning and self-sterilizing surfaces, as well as air and water purification. ${ }^{15}$ In addition titanium dioxide has many advantages as long-term stability, low cost, availability, and nontoxicity towards both humans and the environment. ${ }^{16}$ Among the three most common structures of $\mathrm{TiO}_{2}$ (anatase, rutile and brookite), the most effective photocatalytic effects are observed for titania P25, containing a coexistence of two phases, anatase and rutile, with the ratio $4: 1$. The interaction between the two phases is found to favour a high photo-activity compared to bare anatase and rutile. ${ }^{17}$

Recently, titanium dioxide has been combined with carbonbased nanomaterials to improve the photocatalytic properties of these nanomaterials in different fields, from water purification to energy conversion. ${ }^{\mathbf{1 8 , 1 9}}$ In particular, among carbon nanomaterials, graphene oxide (GO) has been widely investigated as high capacity and selective adsorbent for water contaminants such as organic dyes directly dispersed in water. $^{\mathbf{2 0 , 2 1}}$ Indeed the release of organic colorants in the ecosystem causes several deleterious effects, such as eutrophication and perturbations in the aquatic life.

GO is formed by graphene layers including oxygen functionalities such as hydroxyl, epoxide, carbonyl and carboxyl groups. ${ }^{22}$ The possibility to increase the adsorption ability and selectivity of GO has been investigated by varying the quantity and quality of oxygen functional groups by other kinds of functionalization, ${ }^{21,23}$ by thermal reduction or laser irradiation. ${ }^{\mathbf{2 0 2 4}}$ For example, sulfonated GO powder obtained by organic functionalization showed an increased ability to adsorb methylene blue (MB) with respect to GO powder. ${ }^{21}$ The laser treated GO was also tested for antibacterial activity. ${ }^{24}$ Furthermore, GO in combination with $\mathrm{TiO}_{2}$ nanoparticles (NPs) was used to enhance the photocatalytic activity of the inorganic nanomaterial. ${ }^{20}$

In the case of photocatalytic nanomaterials directly dispersed in water for purification purposes, their removal from water after the use is required, otherwise they could cause further pollution in the environment. To get rid of this problem, the coupling of nanomaterials with membrane technology seems promising, also in view of reusing the same photocatalyst several times.

In previous works, ${ }^{21,23,25}$ we have already reported about the preparation of nanocomposite membranes (containing GO or $\mathrm{TiO}_{2}$ embedded in a Nafion ${ }^{\circledR}$ (DuPont) polymer) for the removal of azo-dyes, from aqueous solution. 
In this work, as an alternative to Nafion, for the first time Nexar ${ }^{\mathrm{TM}}$ polymer was used in combination with inorganic and carbon nanomaterials to obtain new nanocomposite membranes that were tested for the removal of organic contaminants from water. The nanocomposites were tested as adsorbents or photocatalysts under UV-vis light irradiation for the removal of two dyes, Methylene Blue (MB) and Methyl Orange (MO). The structural formulae of these two molecules, which differ for their superficial charge, are reported in Fig. S1 of ESI. $\dagger$ The results reported in the present work show that such hybrid nanocomposites remove effectively different azo dyes by adsorption or photocatalytic degradation. Finally, the regeneration and reuse of the composites is shown, demonstrating that these systems are efficient and environmentally more friendly than the nanomaterials directly dispersed as powder in aqueous solution.

\section{Experimental}

\subsection{Materials}

A sulfonated pentablock copolymer poly( $t$ BS-HI-sS : S-HI- $t$ BS $)$ solution with 10-12 wt\% polymer in a cyclohexane/heptane mixed solvent, was provided by courtesy of Kraton Polymers LLC. A scheme of this copolymer, commercially available as Nexar ${ }^{\mathrm{TM}}$, is reported in Fig. 1. The IEC value of the commercial polymer is 2.0 meq. $\mathrm{g}^{-1}$ corresponding to a sulfonation degree of $52 \mathrm{~mol} \%$. The molecular weight is $112500 \mathrm{~g} \mathrm{~mol}^{-1}$ and the volume fraction $(t \mathrm{BS}-[\mathrm{sS}: \mathrm{S}]-\mathrm{HI})$ is $0.300-[0.226: 0.208]-$ 0.266 . $^{26}$

GO $4 \mathrm{mg} \mathrm{mL}{ }^{-1}$ water dispersion was supplied by Graphenea. P25 titania (>99.5\%) nanoparticles, $N, N$-dimethylformamide (DMF $\geq 99.8 \%$ ) were purchased at ACS reagent. Hydrochloric acid ( $\mathrm{HCl} 37 \%)$, methylene blue $\left(0.05 \mathrm{wt} \%\right.$ in $\left.\mathrm{H}_{2} \mathrm{O}\right)$ and methyl orange $\left(0.1 \mathrm{wt} \%\right.$ in $\left.\mathrm{H}_{2} \mathrm{O}\right)$ were purchased at Sigma-Aldrich.

\subsection{Membranes preparation}

s-PBC membranes and hybrid s-PBC nanocomposite membranes containing as fillers $\mathrm{P}_{2} 5 \mathrm{TiO}_{2}$ nanoparticles (s-PBC$\mathrm{TiO}_{2}$ ) or GO (s-PBC-GO) were prepared by the solvent casting method. In particular, $2.5 \mathrm{~g}$ of commercial s-PBC solution were dried at about $60{ }^{\circ} \mathrm{C}$ to get the evaporation of the commercial solvents and then dissolved in $10 \mathrm{~mL}$ of DMF (as revealed by the clear colour of the solution). Finally, the suspension was cast on a Petri dish at $60{ }^{\circ} \mathrm{C}$ overnight for the complete evaporation of the solvent.

In the case of nanocomposites, the filler solution $(12 \mathrm{mg}$ of P25 $\mathrm{TiO}_{2}$ nanoparticles or GO completely dispersed in $10 \mathrm{~mL}$ of DMF) was added slowly to the DMF polymer solution prepared as described above. This final solution was stirred for several hours to get a homogeneous mixture. Then it was stirred at $80{ }^{\circ} \mathrm{C}$ until the final volume was around $10 \mathrm{~mL}$ and the solution was dense enough to be cast as described for the s-PBC membrane; afterwards the membranes were removed from the Petri dish by dipping the glass plate in deionized water for several minutes. Finally, they were put and pressed between two Teflon plates and heated in oven at ambient condition at $150{ }^{\circ} \mathrm{C}$ for about $25 \mathrm{~min}$. The membranes were soaked and washed in deionized water (Millipore Advantage A10) at room temperature in order to remove eventual impurities, such as residual acids, until the soaking solution stabilized at neutral $\mathrm{pH}^{\mathbf{1 0}}$

After adsorption/photocatalysis experiments, the membranes were processed in order to release the adsorbed dye molecules. The regeneration process is performed by boiling the membranes in deionized water for $15 \mathrm{~min}$, and drying at $80{ }^{\circ} \mathrm{C}$ on a hot plate for $30 \mathrm{~min}$ before each use.

\subsection{Characterization}

Morphology and chemical mapping of the samples was performed by a field emission scanning electron microscope (Zeiss Supra35 FE-SEM) equipped with EDX microanalysis system (Oxford Instruments, X-MAX $80 \mathrm{~mm}^{2}$ ). In order to analyse the cross section of the membranes, they were dipped in liquid nitrogen, where they become stiff, and then they can be easily broken in two parts. Raman analysis was performed using as excitation source a $785 \mathrm{~nm}$ laser and spectra were collected in single spectrum mode with an integration time of $10 \mathrm{~s}$, with a WITec alpha300R confocal instrument and a Nikon $100 \times$ objective. The crystalline structure of the annealed samples was studied by X-Ray Diffraction (XRD) analyses performed with a Bruker-AXS D5005 diffractometer by using a $\mathrm{Cu} \mathrm{K}_{\alpha}$ radiation with an incidence angle of $1.0^{\circ}$; the detection angle $2 \theta$ was varied between $5^{\circ}$ and $62^{\circ}$. Thermogravimetric studies were performed in a temperature range between $100{ }^{\circ} \mathrm{C}$ and $1000{ }^{\circ} \mathrm{C}$ with a $10{ }^{\circ} \mathrm{C} \mathrm{min}^{-1}$ ramp under nitrogen on a TA Q500 instrument.

The photocatalytic activity of the membranes was investigated by evaluating the degradation of $\mathrm{MO}$ and $\mathrm{MB}$ in water solution under UV-vis light irradiation using an initial concentration of $2 \times 10^{-5} \mathrm{M}$ and $1.5 \times 10^{-5} \mathrm{M}$, respectively. The irradiation was performed by a $18 \mathrm{~W}$ UVA/blue DULUX OSRAM lamp. The photocatalytic experiment was carried out by dipping one membrane piece of about $1 \mathrm{~cm}^{2}$ and thickness about 100 $\mu \mathrm{m}$ into $2 \mathrm{~mL}$ of dye solution and by measuring the changes in the absorbance spectra after irradiation by an UV/Vis AGILENT Cary 50 spectrophotometer, in a wavelength range between 200 and $800 \mathrm{~nm}$, using wide optical window cuvettes (200-2500 nm). In particular, the dye degradation was evaluated by means of the Lambert-Beer law, considering the absorbance peaks at $465 \mathrm{~nm}$ and $664 \mathrm{~nm}$ for MO and MB, respectively. For each experiment we have evaluated the contribution of dye adsorption phenomena (under dark conditions) in order to distinguish the photocatalytic activity of each material. The adsorption and photocatalytic experiments were conducted at neutral $\mathrm{pH}$ for $\mathrm{MB}$, and at neutral and acid conditions $(\mathrm{pH}=2$ or $\mathrm{pH}=3.2)$ for MO solution. The $\mathrm{pH}$ value was varied by adding hydrochloric acid. In the case of acid condition, the MO degradation was evaluated by considering the absorbance peaks that, in this case, is shifted to $510 \mathrm{~nm}$. The $\mathrm{pH}$ value of the solutions was measured by a Mettler Toledo SevenGO duo SG23 pH-meter.

The water uptake value of each membrane is calculated in the following way, by using a microbalance:

$$
\text { Uptake } \%=\left[\left(m_{\text {wet }}-m_{\text {dry }}\right) / m_{\text {dry }}\right] \times 100
$$


Table 1 The water uptake values for S-PBC and for hybrid nanocomposite s-PBC membranes with $\mathrm{TiO}_{2}$ and $\mathrm{GO}$

\begin{tabular}{ll}
\hline Membrane & Water uptake (\%) \\
\hline S-PBC & $201 \%$ \\
S-PBC-GO & $308 \%$ \\
S-PBC-TiO & $182 \%$
\end{tabular}

where, $m_{\mathrm{dry}}$ is the mass of the membrane dried in oven at $60{ }^{\circ} \mathrm{C}$ for $2 \mathrm{~h}$ and then put in a desiccator; $m_{\text {wet }}$ is the weight of the membrane after soaking in distilled water at room temperature for 48 hours and quickly wiped with a paper tissue in order to remove most of the free surface water. The calculated values are reported in Table 1.

\section{Results and discussion}

\subsection{Morphological analysis}

Before the photocatalytic test on the hybrid polymeric systems, morphological and chemical characterization of the samples was performed. Photos of the nanocomposite membranes and SEM images of their cross sections are reported in Fig. 2. The sPBC polymer (Fig. 2a) is yellowish with a flat surface; the colour changed from yellowish to black or to white introducing GO (Fig. 2b) and $\mathrm{TiO}_{2}$ (Fig. 2c), respectively. SEM analysis shows that s-PBC membrane (Fig. 2d) is quite smooth and homogeneous; the white irregular vertical lines in the cross sectional image of s-PBC are due to the breaking of the membrane intentionally produced for cross section analysis. In the case of s-PBC-GO (Fig. 2e) the filler is completely and homogeneously dispersed through the entire volume of the polymeric matrix and the nanocomposite membrane shows a spongy structure, with graphitic planes well visible. On the contrary, in s-PBC$\mathrm{TiO}_{2}$ membrane (Fig. 2f), titania nanoparticles are distributed throughout all the section but some agglomerates are evident. The thickness of all the membranes is about 100-110 $\mu \mathrm{m}$. The presence and the chemical composition of the fillers in the membranes are verified by EDX analysis (see Fig. S2 of ESI $\dagger$ ).

The first effect of dispersing nanomaterials inside the polymer is a change of the water uptake values with respect to fillerfree s-PBC, as reported in Table 1 . Compared to the polymer itself, the highly porous structure of GO nanocomposite, joined with the hydrophilic character of GO, is responsible of the increased water adsorption ability; on the contrary, titania agglomerates reduce this value. The complete dispersion of GO planes and the presence of titania agglomerates into the polymeric matrix are confirmed by other characterization techniques and affect the dye removal performance of the nanocomposites, as we will show in the following paragraphs.

\subsection{Spectroscopic and structural analysis}

Fig. 3 shows Raman spectra of s-PBC (black curve), s-PBC-TiO (green curve) and s-PBC-GO (red curve). The Raman peaks observed for s-PBC are in agreement with those reported in the literature, ${ }^{\mathbf{2 6 - 3 0}}$ despite we prepared the membrane re-dispersing
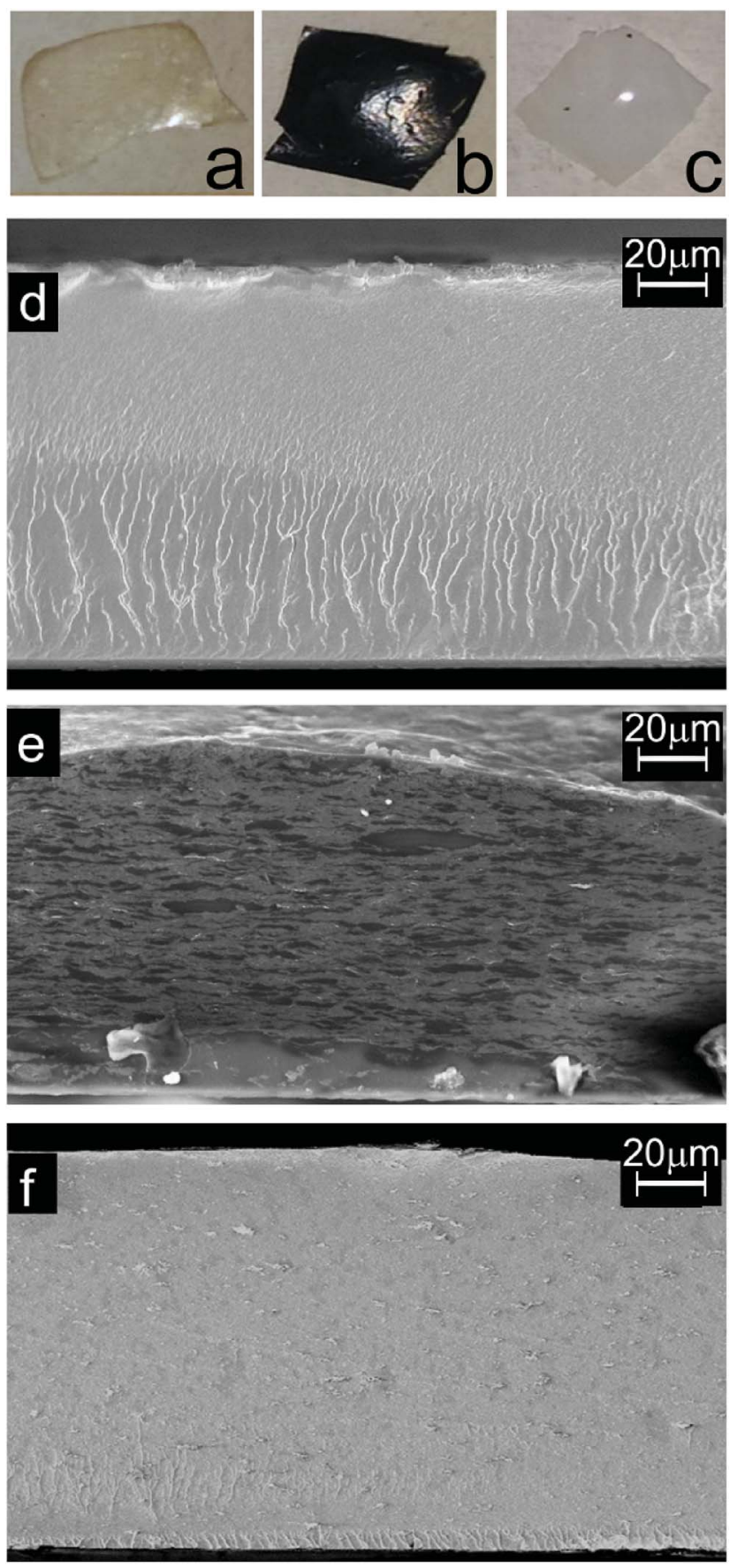

Fig. 2 Photos and cross-sectional SEM images of s-PBC (a, d), s-PBC$\mathrm{GO}(\mathrm{b}, \mathrm{e})$ and s-PBC- $\mathrm{TiO}_{2}$ (c, f) membranes.

the commercial polymer into the DMF polar solvent. The assignments are reported in Table SA of ESI. $\dagger$

In $\mathrm{s}-\mathrm{PBC}-\mathrm{TiO}_{2}$ the features typical of the polymer are still visible with the addition of further peaks related to titania at 136, 397, 515 and $638 \mathrm{~cm}^{-1}$ (indicated by the magenta stars), associated respectively to the $\mathrm{E}_{\mathrm{g}}, \mathrm{B}_{1 \mathrm{~g}}, \mathrm{~A}_{1 \mathrm{~g}} \& \mathrm{~B}_{2 \mathrm{~g}}$, and $\mathrm{E}_{2 \mathrm{~g}}$ modes of the anatase phase.

The peak at $638 \mathrm{~cm}^{-1}$ in the s-PBC- $\mathrm{TiO}_{2}$ composite is due to the superposition of two signals: the sulfonilic bending of the polymer and $\mathrm{E}_{2 \mathrm{~g}}$ modes of titania. 


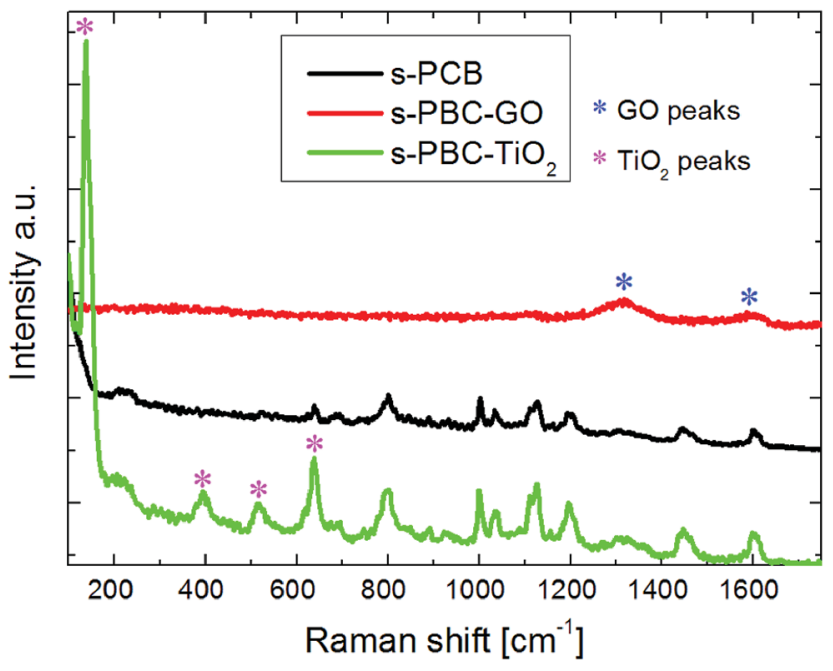

Fig. 3 Raman spectra of the s-PBC polymer (black curve) and of the hybrid composite with $\mathrm{TiO}_{2}$ (green curve) and $\mathrm{GO}$ (red curve). The stars indicate the peaks associated to the graphene oxide and crystalline titania phase.

For s-PBC-GO, the peaks of the polymer are not visible in the Raman spectrum of the composite and only the D and G bands associated to GO (indicated by the blue stars) ${ }^{20}$ are present. In this case, the absorption coefficient of GO at the laser wavelength, block the incoming radiation and limits the detection of the overall Raman signal to few hundreds nanometers, thus limiting the collection of the polymeric Raman features. In order to investigate the crystallinity degree of the organic-inorganic composite membranes and the grade of nanomaterial dispersion inside the polymeric matrix, XRD analysis was performed. The average chain spacing of a polymer can be interpreted as $d$ spacing calculated by Bragg's law $n \lambda=2 d \sin \theta$, where $n$ is an integer number, $\lambda$ is the X-ray wavelength, $d$ is the spacing between the polymeric chains, and $\theta$ is the diffraction angle.

Fig. 4 shows the XRD spectra of s-PBC (black curve), s-PBC$\mathrm{TiO}_{2}$ (green curve) and s-PBC-GO (red curve). The polymeric membrane shows a broad peak at $17^{\circ}$ corresponding to a $d$ space value of $2.6 \AA$. This broad peak is typical of an amorphous structure. ${ }^{31}$ The same peak is also observed for $\mathrm{s}-\mathrm{PBC}-\mathrm{TiO}_{2}$ and $\mathrm{s}-\mathrm{PBC}-\mathrm{GO}$. In the XRD spectrum of $\mathrm{s}-\mathrm{PBC}-\mathrm{TiO}_{2}$ peaks related to the anatase and rutile crystalline phases of the nanofiller are visible, as indicated by the magenta and blue stars respectively. ${ }^{32}$ For $\mathrm{S}-\mathrm{PBC}-\mathrm{TiO}_{2}$ the nanomaterial is agglomerated inside the matrix. In the case of s-PBC-GO, on the contrary, the peak of GO expected at $10^{\circ}$ (indicated by the circle) ${ }^{33}$ is not so evident in the XRD spectrum, indicating that GO is completely dispersed and mixed within the polymer, in agreement with the morphological characterization (SEM and EDX, see Fig. 2 and $\mathrm{S} 2 \dagger$ ). In addition, a shoulder around $28^{\circ}$ is observable for s-PBC and s-PBC-GO, while it is less evident for $\mathrm{s}-\mathrm{PBC}-\mathrm{TiO}_{2}$ : this seems to be related to the sulfonilic groups inside the polymer and due to the interaction with water molecules present in the atmosphere and trapped by the membrane.

Indeed, the intensity of this strong band at $28{ }^{\circ} \mathrm{C}$ is higher in the XRD spectrum of wet s-PBC (not shown) than in the case of

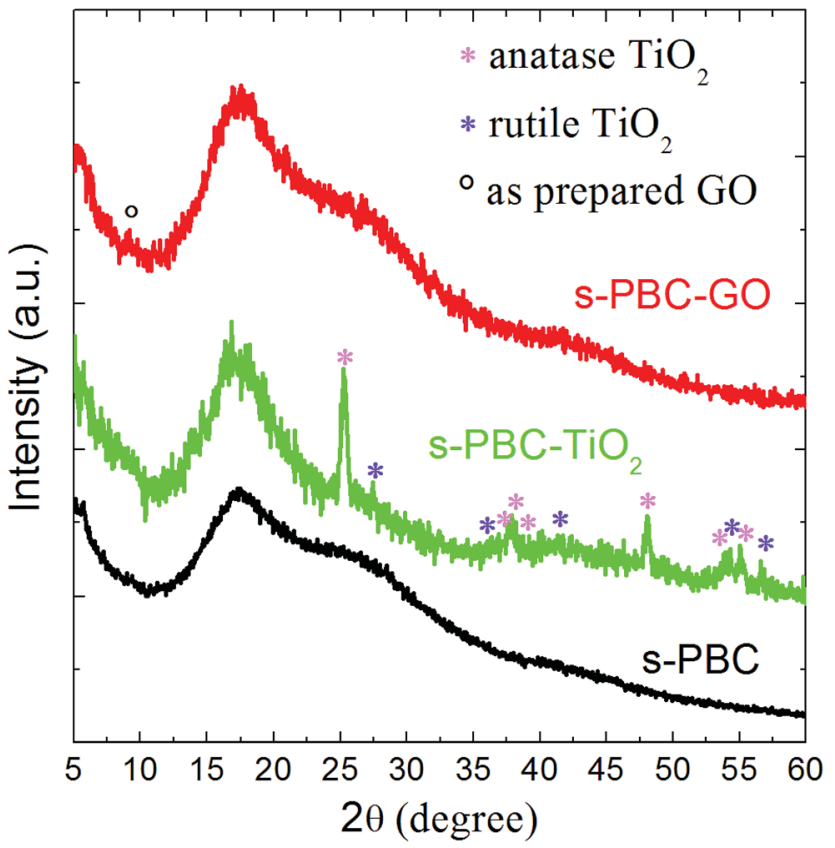

Fig. 4 XRD spectra of the s-PBC polymer (black curve) and the hybrid composites s-PBC- $-\mathrm{TiO}_{2}$ (green curve) and s-PBC-GO (red curve). The pink and violet stars indicate the peaks associated to the anatase and rutile titania phases, respectively, while the circle evidences the diffraction peak related to GO.

dried membranes discussed in this paper. These results are in good agreement with the water uptake values reported in Table 1: indeed, in the case of $\mathrm{s}-\mathrm{PBC}-\mathrm{TiO}_{2}$ the water content is lower than in the case of pure polymer or s-PBC-GO, and thus the peak at $28^{\circ}$ is less evident. The minor water uptake of the titania containing composite can be ascribed to the aggregation of $\mathrm{TiO}_{2}$ particles inside the polymer and, probably, to their interaction with the sulfonilic groups. This interaction can be due to the sPBC structure: ${ }^{34}$ the s-PBC polymers have micellar structures that change depending on the choice of the solvent (polar or apolar) used. A different interaction of GO with the polymeric micelles is supposed to cause a complete dispersion of the GO sheets inside the polymer. This can be ascribed to the different morphology of the two investigated nanomaterials (flakes $v s$. spheres) and their chemical (electrostatic or hydrophobic) interactions with the polymers.

Fig. 5 shows the overall thermal weight losses (Fig. 5a) and the derivative weight losses as a function of the temperature (Fig. 5b) for s-PBC polymer (black curves), s-PBC-TiO ${ }_{2}$ (green curves) and s-PBC-GO (red curves). s-PBC exhibits three distinct degradation steps (Fig. 5a): at low temperature, below $150{ }^{\circ} \mathrm{C}$, the small weight loss of about $5 \%$ can be mainly associated to the removal of residual water within the membrane. The second weight loss between $260{ }^{\circ} \mathrm{C}$ and $400{ }^{\circ} \mathrm{C}$ is due to the desulfonation process and the last one, above $400{ }^{\circ} \mathrm{C}$, is associated to thermal degradation of the polymer main chain. ${ }^{26}$ Fig. $5 \mathrm{~b}$ shows the derivative of weight loss for the polymer and the composites between $50{ }^{\circ} \mathrm{C}$ and $600{ }^{\circ} \mathrm{C}$ : two main peaks are present in this range and are related to de-sulfonation of the polymer and the degradation of backbone. For s-PBC (black 

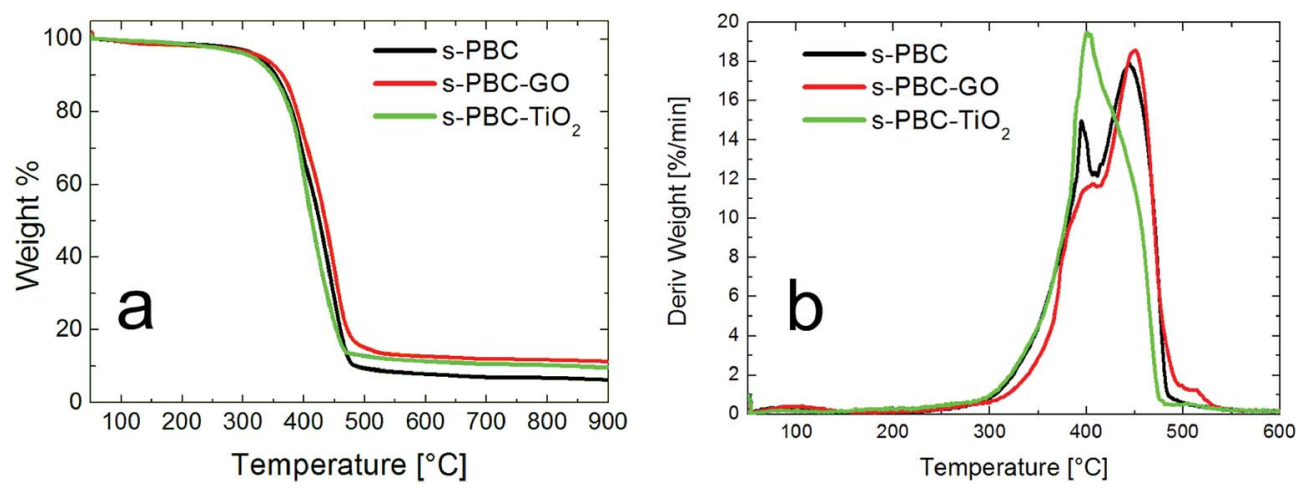

Fig. 5 TGA analysis showing the overall thermal weight losses (a) and the derivative weight losses (b) as a function of temperature for s-PBC polymer (black curves) and hybrid membranes with $\mathrm{TiO}_{2}$ (green curves) and $\mathrm{GO}$ (red curves).

curve), the first peak at $395{ }^{\circ} \mathrm{C}$ is very sharp, indicating that thermal degradation of sulfonilic group occurred rapidly and completely, whereas the backbone degradation occurred at $444{ }^{\circ} \mathrm{C}$.

s-PBC-GO shows a better thermal stability than s-PBC: the thermal decomposition is shifted to $451{ }^{\circ} \mathrm{C}$ and the peak at about $395^{\circ} \mathrm{C}$ is only a shoulder, suggesting a modification of the sulfonilic contribution. On the contrary, s-PBC- $\mathrm{TiO}_{2}$ (green curve of Fig. 5b), has a different shape with respect to the other two curves. The first peak is as sharp as in the case of the polymer (black curve), but more intense, whereas a significant decrease of the second peak intensity is observed. This suggests a different interaction of $\mathrm{TiO}_{2}$ with the polymer and in particular with the hydrophilic groups, that makes this composite more thermally unstable.

Thermogravimetric analyses, therefore, confirms that the inorganic particles and the GO layers disperse in a different way within the polymeric matrix, in agreement with the previous analysis.

\subsection{Photocatalytic activity}

Recently, we have shown that for removing dyes from water it is more convenient to use nanocomposite membranes instead of nanomaterials dispersed in water. In that work, we have shown the use of another sulfonated polymer (Nafion) to prepare nanocomposites containing various nanomaterials (titanium dioxide, graphene oxide and sulfonated graphene oxide). ${ }^{21,23,25}$ The addition of nanomaterials to the polymer, and the increased hydrophilicity of the formed nanocomposites, resulted in an improvement of the dye removal performance with respect to the polymer itself or to the nanomaterials directly dispersed in water. ${ }^{21,23,25}$

The s-PBC polymer investigated in the present work is not only cheaper than Nafion, but it has higher acidity and hydrophilicity as confirmed by the comparison between the water uptake values of the two polymers (i.e. $24 \%$ for Nafion and $201 \%$ for s-PBC), thus we expect better photo-catalytic properties. The IEC (i.e. milliequivalents (meq.) of sulfonic acid per gram of dry polymer) value of the s-PBC polymer and Nafion polymer used in our works are 2.0 and 0.9 meq. $\mathrm{g}^{-1}$, respectively. In the case of
s-PBC the density of the sulfonated groups is higher than Nafion.

The degradation ability of the polymer and the nanocomposite membranes has been tested onto different dyes (MO and MB), having different superficial charge (see Fig. S1 of ESI $\dagger$ ), in dark or under irradiation. In this way, we can evaluate how the charge interaction between dye molecules and membranes affects the removal efficiency.

3.3.1. Removal of methylene blue. $\mathrm{MB}$ is a cationic, thiazine dye, with an absorbance band centered at $664 \mathrm{~nm}\left(\mathrm{n}-\mathrm{n}^{*}\right)$ (monomer) with a shoulder at $610 \mathrm{~nm}$ related to the $\mathrm{MB}$ dimer. ${ }^{20,21}$

Fig. 6 shows the residual methylene blue concentration (calculated by the variation of the dye monomer peak) for the solutions where the s-PBC membrane and the composites were immersed for three hours in dark (blue bars) or under irradiation (cyan bars). In absence of polymeric materials, under UVA/ blue irradiation for the same time, MB did not show any degradation. ${ }^{25}$

All the materials are able to remove more than the $90 \%$ of the initial MB concentration either in dark or under irradiation. This is probably due to the electrostatic interaction between MB positive superficial charge and the negative charge of sulfonilic groups present on the membranes. MB is removed without the formation of any precipitates or flocculates in the beaker as occurred when using the powder directly dispersed in the solution. ${ }^{21}$ The photos in Fig. 6 shows the membranes after the adsorption or irradiation processes (see the black arrows): their color change to blue, due to the interaction with $\mathrm{MB}$, with the exception of s-PBC-GO due to its initial black color. For s-PBC$\mathrm{GO}$, the degradation efficiency is higher under irradiation, while the s-PBC and the s-PBC- $-\mathrm{TiO}_{2}$ membranes show the best efficiency in dark. In order to explain this behavior, a more detailed investigation requires a more careful analysis of the absorbance spectra, as reported below.

Fig. 7 shows the absorbance spectra of initial MB solution and the final dye solutions containing the membranes after three hours in dark (Fig. 7a) or under irradiation (Fig. 7b). As just described in Fig. 6, the membranes significantly reduce the MB concentration in both conditions. Compared to the initial MB spectrum (blue curves), the shape of the absorbance spectra 


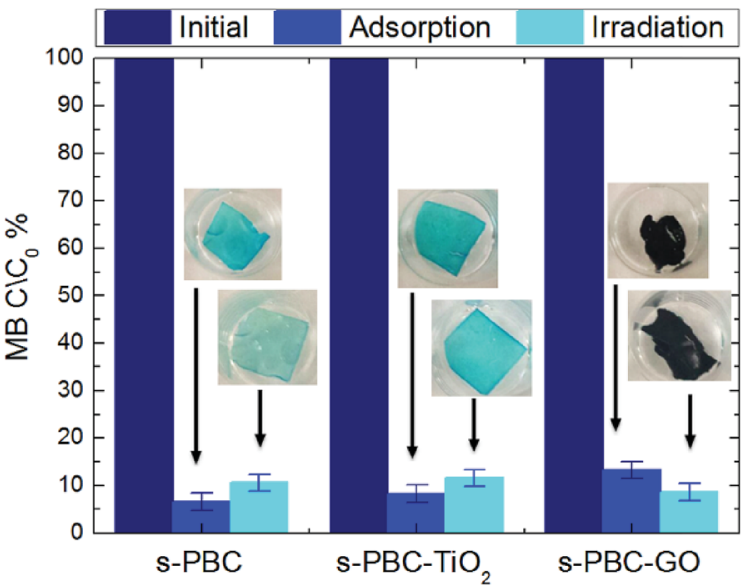

Fig. 6 Residual concentration of $\mathrm{MB}$ after three hours in contact with $\mathrm{s}-\mathrm{PBC}, \mathrm{s}-\mathrm{PBC}-\mathrm{TiO}_{2}$ and s-PBC-GO in dark (blue bars) or under UVA/ blue light irradiation (cyan bars). The navy blue bars represent the initial $\mathrm{MB}$ concentration (i.e. $1.5 \times 10^{-5} \mathrm{M}$ ).

of the dye solutions changed after being in contact with the membranes. In particular, after 3 hours of adsorption, the predominance of the peak related to MB dimers with respect to the peak of the monomer is observable for all the membranes (see insect of Fig. 7a). The best adsorption performance is recorded for s-PBC (black curve of Fig. 7a).

In the case of irradiation, the monomer peak is higher than the one related to the dimers only for $\mathrm{s}-\mathrm{PBC}-\mathrm{TiO}_{2}$ (green curve of Fig. 7b). The kinetic of monomers and dimers has been observed for different adsorption and irradiation times (see Fig. S3 in ESI $\dagger$ ) and it depends on the type of process (adsorption or irradiation) and on the specific nanocomposite. In order to understand deeply this aspect, the MB absorbance spectra obtained after contact with the membranes were deconvoluted in three main components related to monomers, dimers and higher order aggregates of the dye, respectively. The MB higher aggregates can be clearly evidenced by the appearance of a peak at $577 \mathrm{~nm} .^{20,21}$ Fig. 8a shows an example of deconvolution of the
MB UV-vis absorbance spectrum in the aforementioned main components. These components allow to measure the residual concentration of dye monomers (M), dimers (D) and higher aggregates (P) versus time of contact with s-PBC, s-PBC- $\mathrm{TiO}_{2}$ and s-PBC-GO, in the dark (closed symbols) and under irradiation (opened symbols), as reported respectively in Fig. 8b-d.

In the presence of s-PBC polymer, during the adsorption process, $\mathrm{MB}$ monomers and dimers decrease at the same way and almost linearly with time. Higher order aggregates form in the first 5 minutes of contact of the solution with the polymer and then they are removed (adsorbed) with time. Anyway, their final concentration in solution remains higher than the monomer and dimer concentration.

In the case of irradiation, the removal efficiency of monomers (cyan curve) and dimers (magenta curve) seems to be faster at the beginning, but finally it reaches the same value obtained with the adsorption. Vice versa, for higher aggregates, the photocatalytic degradation is slower and it looks very similar to the dye removal trend due to the adsorption process. Fig. $8 \mathrm{c}$ and $\mathrm{d}$ show the kinetic of monomers, dimers and higher aggregates for the $\mathrm{MB}$ solution in contact with, respectively, sPBC- $-\mathrm{TiO}_{2}$ and s-PBC-GO, both in dark conditions or under irradiation. As for s-PBC, monomers and dimers in contact with the membrane in dark decrease with time. The adsorption occurs mainly in the first minutes of contact and, finally, they reach almost the same residual concentration. Higher order aggregates (green curves) are formed in the first minutes of contact with s-PBC- $\mathrm{TiO}_{2}$ and even faster for s-PBC-GO, more significantly than for the case of s-PBC. Afterwards they start to decrease but their final concentration remains higher than the dimer and monomer concentrations, as occurred also in the case of s-PBC (Fig. 8b).

Under irradiation (open symbols), monomers and dimers decrease rapidly with time and finally they show almost the same residual concentration; larger aggregates are formed in the first minutes and rapidly decrease down to a concentration value lower than in the case of solution in contact with nanocomposite membranes in dark conditions (closed symbols).

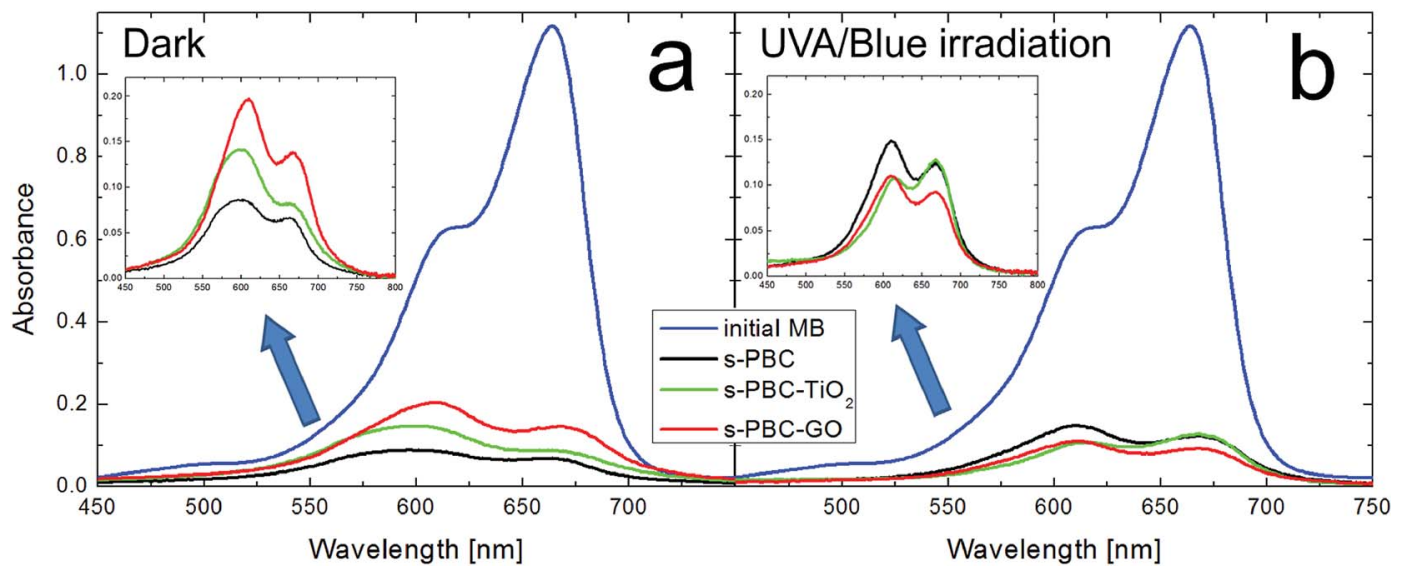

Fig. 7 UV-vis absorbance spectra of initial MB solution (blue curve) and of the dye solution after adsorption in dark (a) and after UVA/blue irradiation (b) for three hours in the presence of s-PBC (black curves), s-PBC- $\mathrm{TiO}_{2}$ (green curves) and s-PBC-GO (red curves) membranes. In the insets, the magnification of the absorbance spectra for the three membranes after three hours are reported. 

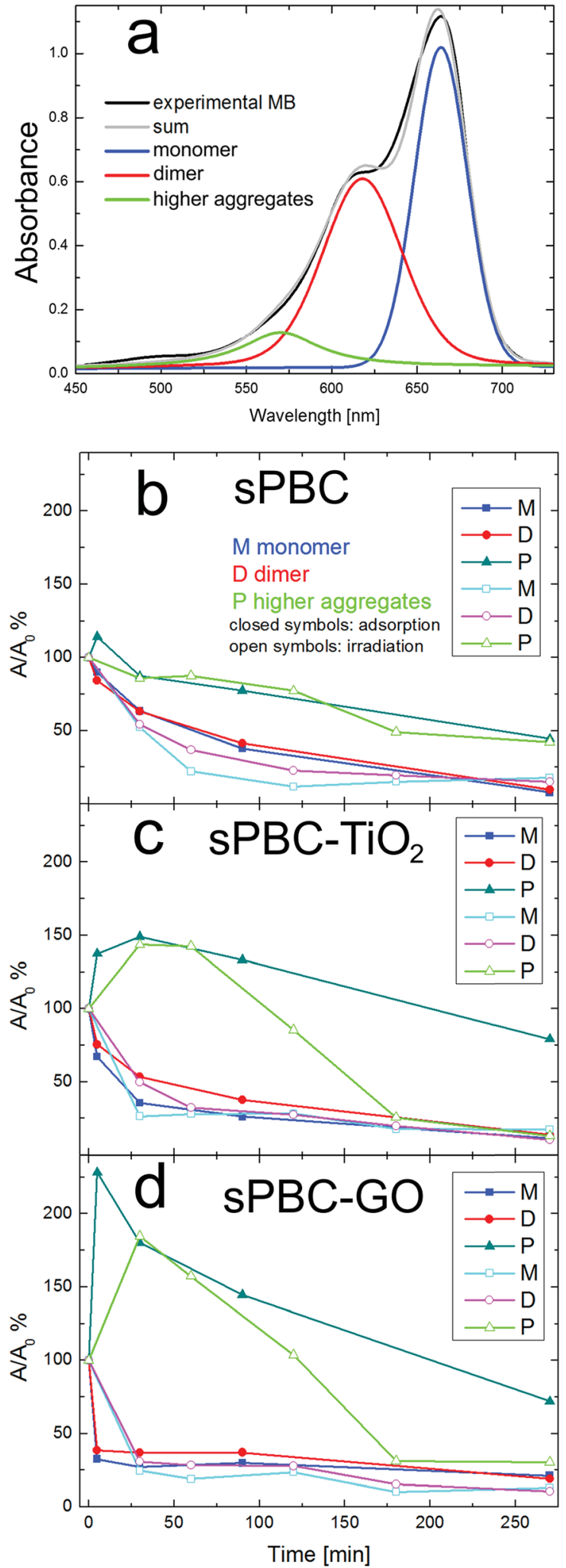

Fig. 8 (a) Deconvolution of MB UV-vis absorbance in three main components related to the monomer (M), dimer (D) and higher aggregates $(P)$ forms of the dye. Residual concentration versus time of contact with s-PBC (b), s-PBC- $-\mathrm{TiO}_{2}$ (c) and s-PBC-GO (d) in the dark (closed symbols) and under irradiation (opened symbols) for dye monomers $(M)$, dimers $(D)$ and higher aggregates $(P)$, respectively.
In summary, all the membranes induce a decrease of monomers and dimers with time, reaching almost the same final concentration for both adsorption and irradiation processes. A different trend is observed for higher order aggregates: they are formed in the first minutes of contact with the membranes (this effect is more important for s-PBC-GO, where the aggregation of the dye molecules is likely favored by the GO planes ${ }^{\mathbf{2 0}}$ ) and then decrease. The nanocomposite membranes under irradiation show a higher efficiency in the removal/degradation of larger aggregates than s-PBC.

The presence/formation of aggregates larger than dimers was not observed in our previous work on Nafion nanocomposites. $^{21}$ This can be ascribed to the structural differences between the two sulfonated polymers or to a modification of the ionic strength of dye solutions when the s-PBC membranes were immersed inside, due to possible release of ions by the same materials.

Moreover, sPBC turns out to be more efficient than Nafion in the removal of $\mathrm{MB}$. In a previous paper, ${ }^{25}$ we reported that the residual concentration of $\mathrm{MB}$ after 3 hours in contact with a piece of Nafion membrane in dark and under irradiation is $30 \%$ and $20 \%$, respectively, while the sPBC polymer is able to remove more than $90 \%$ of $\mathrm{MB}$ in the same experimental conditions. The density of sulfonilic groups in s-PBC is higher (higher IEC number) than in Nafion and this could favour the aggregation and release of higher order $\mathrm{MB}$ aggregates in the solution. Since the adsorption is so high and fast it is not possible to observe evident differences among pristine s-PBC and composites with titania and GO. A deep analysis of the recorded absorbance spectra and their deconvolution in the three components (monomers, dimers and higher aggregates) allows to highlight some differences in the degradation ability of the three materials. The data of Fig. 6 and 7 are related to the removal of the MB monomer (absorbance peak at $664 \mathrm{~nm}$ ) after 3 hours of contact with the membranes. After 5 minutes, the presence of $\mathrm{GO}$ and $\mathrm{TiO}_{2}$ favours the reduction of monomer and dimers with respect to the S-PBC membrane without fillers. The introduction of the fillers in S-PBC accelerates the capacity to form MB aggregates (as shown in Fig. 8) probably due to an increased porosity and surface area of the materials that affect the adsorption capacity of these materials. In addition, we speculate that the aggregation of $\mathrm{MB}$ also depends on the morphology of these materials, in particular on the reorganization of micellae and the orientation of sulfonilic groups,${ }^{34}$ that can be influenced during the preparation of the films by the presence of fillers. These aspects will be the subject of future investigation.

In order to discuss the role played by the polymeric matrix on the dye degradation, a comparison between different dye molecules can be helpful. In the following paragraph the removal of MO by the membranes will be discussed.

3.3.2. Removal of methyl orange. The UV-visible absorbance spectrum of MO dissolved in water at neutral $\mathrm{pH}$ shows two maxima (Fig. 9) at $270 \mathrm{~nm}$ and $465 \mathrm{~nm}$. The absorbance at $270 \mathrm{~nm}$ is assigned to the benzene ring in MO, whereas the absorbance at $465 \mathrm{~nm}$ is due to the azo linkage of MO. ${ }^{35}$ The latter peak was used to quantify the MO removal due to 


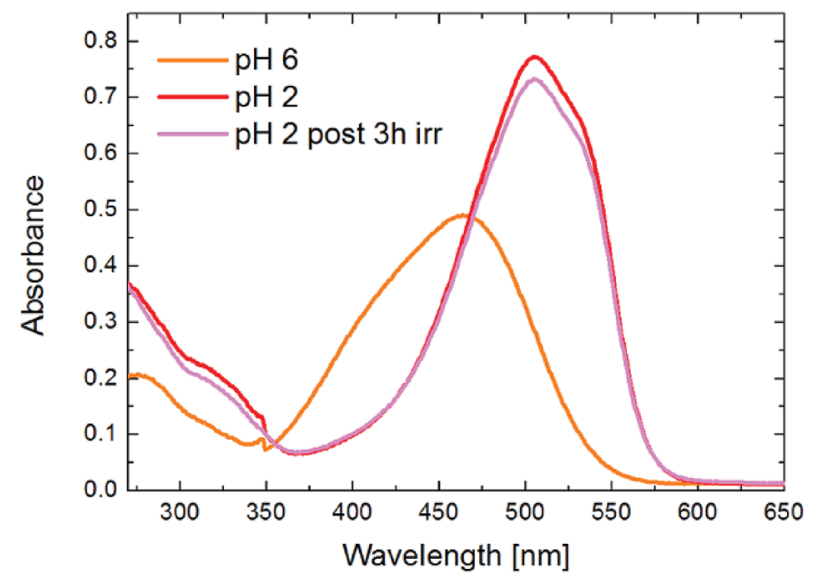

Fig. 9 UV-vis absorbance spectra of $\mathrm{MO}$ (concentration of $2 \times 10^{-5}$ M) at $\mathrm{pH} 6$ (orange curve) and at acid $\mathrm{pH}$ before (red curve) and after UVA/blue irradiation for 3 hours (magenta curve).

adsorption and photocatalysis; the peak at $270 \mathrm{~nm}$ is correlated to the formation of by-products as a consequence of the photodegradation of the azo dye. No degradation of MO took place in the absence of membranes up to $3 \mathrm{~h}$ under UVA/blue irradiation (not shown). Furthermore, analogously to what explained in our previous work $^{23}$ for the case of Nafion membranes, the adsorption of MO on s-PBC membranes is hindered, due to the electrostatic repulsions between the negative molecular charge of the dye and the negative charge of sulfonilic groups in the polymer. At $\mathrm{pH}=2$ the solution changes its colour to red, the absorbance band is shifted towards larger wavelengths, and a shoulder appears at larger wavelength, due to the protonation of $\mathrm{MO}$ (Fig. 9). Even at acidic $\mathrm{pH}$, under UVA/ blue irradiation for three hours only a very small $(<5 \%) \mathrm{MO}$ removal is observed.

Firstly, we tested the degradation ability of the composites at $\mathrm{pH}=6$. Fig. 10 shows the UV-vis absorbance spectra of (a) the initial MO solution (orange curve) and the dye solutions in

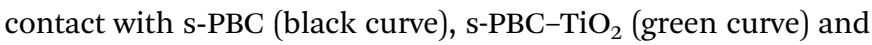
s-PBC-GO (red curve) for one day in dark. In Fig. 10b we report the residual $\mathrm{MO}$ concentration versus time of contact of $\mathrm{MO}$ solutions with the same membranes under UVA-blue light irradiation for 270 minutes. In spite of what we have reported in our previous work ${ }^{23}$ for Nafion polymer, this type of sulfonated polymer and its composites are not able to adsorb the dye even after 24 hours in contact with MO solutions (Fig. 10a), due to electrostatic repulsion between the dye molecules and the sulfonilic groups. Under irradiation (Fig. 10b) the s-PBC polymer and the composite with GO are not able to degrade the dye, while only a moderate $(20 \%)$ degradation efficiency for the composite with titanium dioxide is obtained. It is well known that $\mathrm{TiO}_{2}$ nanopowder can effectively degrade MO under UVlight illumination, ${ }^{23}$ but s-PBC- $\mathrm{TiO}_{2}$ composite shows a low degradation efficiency although titanium dioxide is present. This can be explained by the reduced interaction of $\mathrm{TiO}_{2}$ embedded in the membrane with the dye molecules. Owing to the fact that we did not observe any adsorption within 24 hours of contact of the materials with the dye, we lowered the $\mathrm{pH}$ value of the dye solution down to 2. Indeed, in our previous work ${ }^{23}$ we demonstrated that MO adsorption on the composites increased by lowering the solution $\mathrm{pH}$ : as the dye adsorbs on the polymeric surface, protons are released from the polymer and induce protonation of the dye molecules in solution, therefore increasing the dye adsorption. Therefore, from the experiment performed in acidic condition, we observe that the s-PBC membranes are able to adsorb protonated $\mathrm{MO}$ molecules and also show a photocatalytic activity.

Fig. 11 shows the residual concentration of $\mathrm{MO}$ at $\mathrm{pH}=2$ after one, two and three hours of adsorption in dark or UVA/ blue light irradiation in contact with s-PBC, s-PBC- $\mathrm{TiO}_{2}$ and s-PBC-GO.

After 3 hours in dark, the polymer is able to adsorb more than the $20 \%$ of initial MO concentration, and a similar effect is observed for the membrane with $\mathrm{TiO}_{2}$. GO enhances the MO removal efficiency of the polymer, which reaches the $50 \%$ of the initial dye concentration. Irradiation has the effect of increasing not only the final amount of removed MO but also the degradation rate. The addition of the fillers enhances the degradation/removal effects. In particular, after one hour of
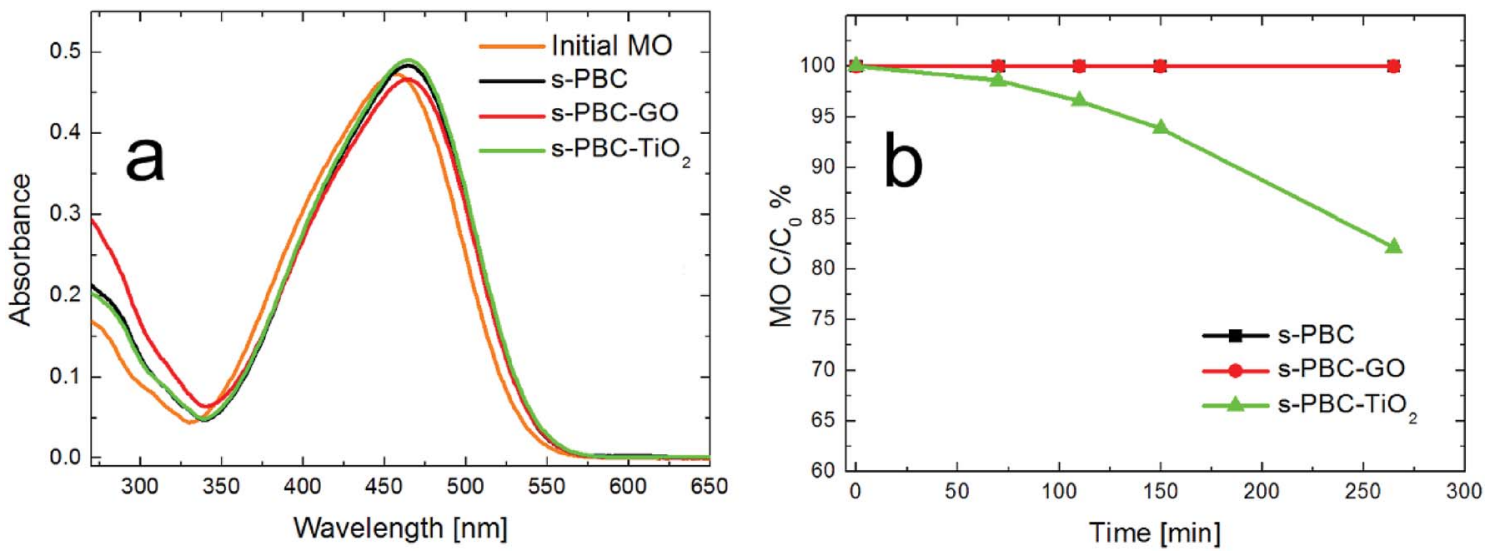

Fig. 10 (a) UV-vis absorbance spectra of initial MO solution ( $C=2 \times 10^{-5} \mathrm{M}$ ) and of dye solutions in contact with s-PBC (black curve), s-PBC$\mathrm{TiO}_{2}$ (green curve) and s-PBC-GO (red curve) for one day in dark at $\mathrm{pH}$ 6. (b) Residual MO concentration versus time of contact of $\mathrm{MO}$ solutions at $\mathrm{pH} 6$ with s-PBC (black curve), s-PBC- $\mathrm{TiO}_{2}$ (green curve) and s-PBC-GO (red curve) under UVA-blue light irradiation. 


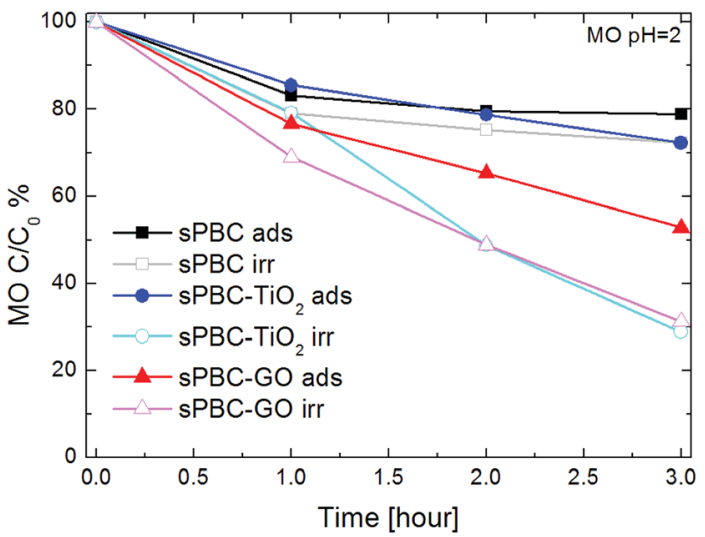

Fig. 11 Residual concentration of $\mathrm{MO}$ at $\mathrm{pH}=2$ versus time of contact with s-PBC (squared symbols), s- $\mathrm{PBC}-\mathrm{TiO}_{2}$ (circular symbols) and sPBC-GO (triangular symbols) in dark (closed symbols) or UVA/blue light irradiation (open symbols). The initial MO concentration is $2 \times$ $10^{-5} \mathrm{M}$.

irradiation, s-PBC-GO membrane shows the higher $\mathrm{MO}$ removal efficiency. This improvement can be explained by the morphological characterization, showing that the membrane structure becomes very porous in the presence of GO, and by the measurement of the water uptake that is higher than for the polymer itself and the s-PBC- $\mathrm{TiO}_{2}$ composite.

In acidic condition, the MO photocatalytic degradation ability is increased under irradiation for all the materials and, in particular, both the composites with $\mathrm{TiO}_{2}$ and $\mathrm{GO}$ are able to remove about $75 \%$ of the initial dye concentration. For a better understanding of the photocatalytic process, we acquired the UV-visible absorbance spectra obtained for the dye solutions (Fig. 12a-c), that were in contact with the membranes, and for the membranes (Fig. 12d-f) before and after the irradiation or adsorption processes. The photos reported as inset in the graphs of Fig. 12d-f show the membranes tested after the adsorption and irradiation processes. As just said, s-PBC is able to reduce MO concentration in acid condition both in dark and under irradiation. The effect is more significant under irradiation and in this case a slight increase of the absorbance curve below $300 \mathrm{~nm}$ is visible. After both processes, in dark and under irradiation, the $\mathrm{s}$-PBC membranes become red due to the contact with (and adsorption of) MO molecules. The absorbance spectra of the polymer before and after the adsorption process are reported in Fig. 12d: the polymer itself does not absorb in the visible region; however, after the adsorption process the typical absorbance peak of the dye molecules appears at about $520 \mathrm{~nm}$, confirming that these are adsorbed into the polymeric matrix. The same occurs after the irradiation process (not reported in the graph). We can conclude that the degradation of MO by the polymer is due mainly to an adsorption phenomenon that is enhanced under irradiation. The irradiance spectrum of the lamp used for the irradiation (see Fig. S4 of ESI†) has its maximum intensity peak at $365 \mathrm{~nm}$ and therefore the light is not directly absorbed by the polymer neither by the MO molecules.

As explained above, the s-PBC-GO composite shows the best removal efficiency in adsorbing $\mathrm{MO}$ and this efficiency increases under irradiation. Since this as-prepared membrane is black, we are not able to see any change in the colour or in the absorbance spectra of the membranes after the processes in MO (Fig. 12e).

Indeed, GO dispersed in the polymer changes the optical properties of the polymer itself and absorbs light in the whole investigated region, as shown by the absorbance spectrum.

In the case of s-PBC-TiO ${ }_{2}$ (Fig. 12c), the removal of MO under irradiation is more significant than in dark conditions. In addition, the appearance of a strong peak below $300 \mathrm{~nm}$ suggests the formation of by-products generated by photocatalytic degradation. ${ }^{36}$ The photos reported in Fig. 12f, show the membranes after the two processes: the colour of the membrane put in contact with MO in dark turns to red, while the piece under irradiation remains almost unchanged. The absorbance spectrum of s-PBC- $\mathrm{TiO}_{2}$ shows an absorption edge at about $380 \mathrm{~nm}$, while the filler-free polymer has an absorption edge at about $275 \mathrm{~nm}$ (see Fig. 12d and $\mathrm{S} 4 \dagger$ ). After dipping the membrane in MO solution in dark, the MO-related peak appears, confirming the adsorption ability of the composite; this peak is not observed after the irradiation process, corroborating the evidence of photocatalytic degradation with no significant adsorption effect.

The best performance for MO removal is recorded for both sPBC-GO and s-PBC-TiO ${ }_{2}$, although the degradation mechanisms induced by $\mathrm{GO}$ and $\mathrm{TiO}_{2}$ in the polymeric nanocomposites are different. For a clearer description, we report in Fig. 13 the UV-vis a comparison among the absorbance spectra of $\mathrm{MO}$ solutions (at $\mathrm{pH}=2$ ) put in contact with $\mathrm{s}-\mathrm{PBC}-\mathrm{TiO}_{2}$ (green and light green curves) and s-PBC-GO (red and magenta curves) for three hours in dark or under irradiation. The initial MO spectrum at $\mathrm{pH}=2$ is also reported as a reference. As already discussed above, the best performance in dark is recorded for the composite with GO. This result is ascribed to the different morphology of this composite with respect to s$\mathrm{PBC}$ and $\mathrm{s}-\mathrm{PBC}-\mathrm{TiO}_{2}$ and to its larger water uptake. Under irradiation, the MO removal efficiency is almost the same for $\mathrm{s}^{-}$ PBC-GO and s-PBC- $\mathrm{TiO}_{2}$.

However, in the case of $\mathrm{s}-\mathrm{PBC}-\mathrm{TiO}_{2}$, we observe the formation of a peak below $300 \mathrm{~nm}$, already evidenced in previous studies, and associated to the formation of aromatic intermediate species, ${ }^{36}$ probably as harmful as the original MO molecules. $^{37}$ In the case of $\mathrm{s}-\mathrm{PBC}-\mathrm{GO}$, the aromatic intermediate compounds are not observed and these results strongly indicate that MO dye removal from water is achieved in a safer way by using a s-PBC-GO membrane instead of a s-PBC-TiO membrane.

In the case of s-PBC-GO it is useful to discriminate between two possible situations: (1) by-products are formed in solution but immediately removed by adsorption on the same membrane or (2) MO is just adsorbed without degradation (no by-products formation). In order to understand this issue, we performed a simple test: two solutions (A and B) containing the by-products (highlighted by the absorbance peak at about 300 $\mathrm{nm}$ ) were produced under 3 hours of irradiation in the presence of two pieces of s-PBC- $-\mathrm{TiO}_{2}$. Then the two solutions are put in contact with s-PBC-GO for one, two and three hours in order to verify the effect on the by-products in dark or under irradiation. 

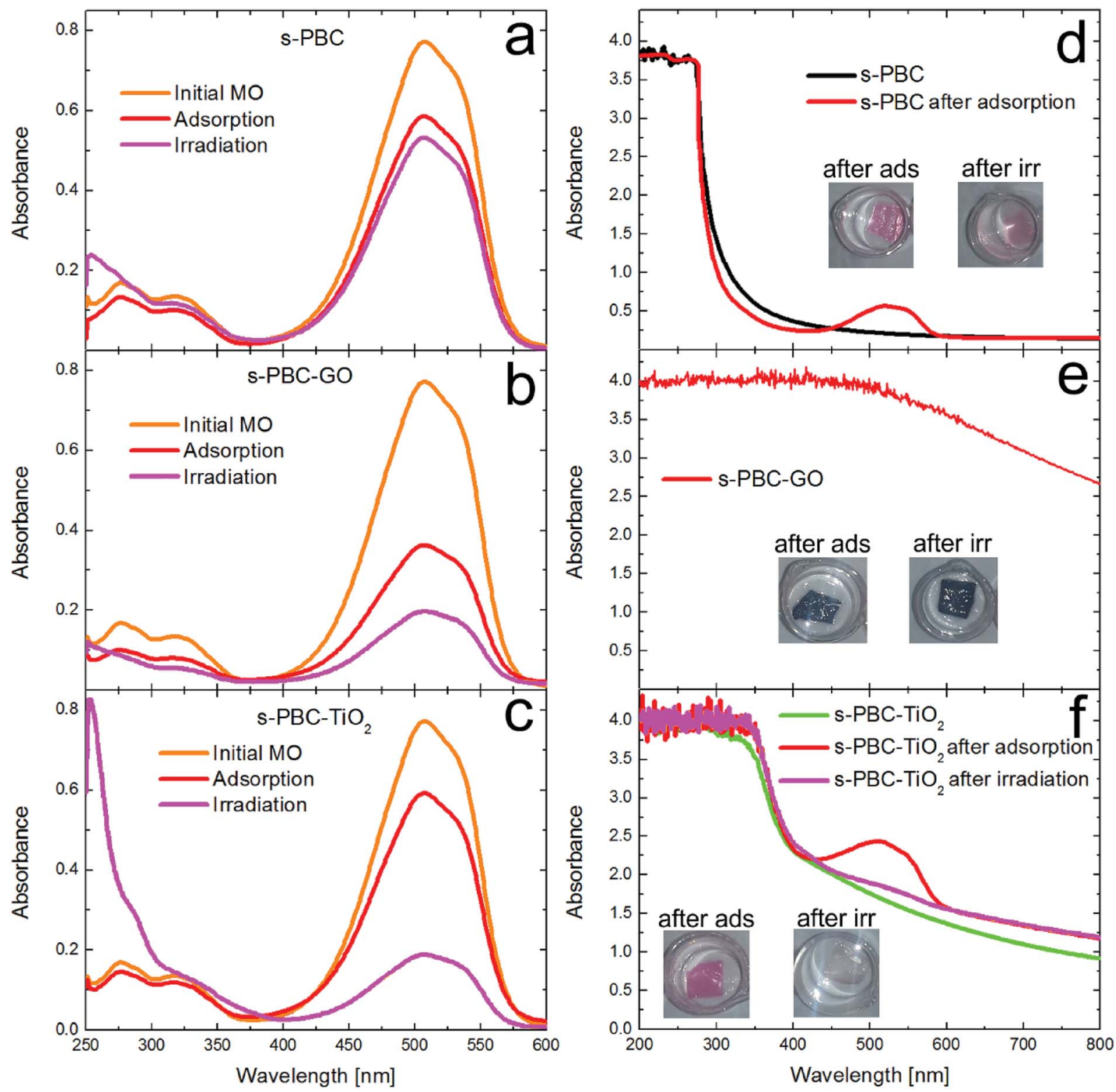

Fig. 12 UV-visible absorbance spectra of MO solutions where (a) s-PBC, (b) s-PBC-GO and (c) s-PBC-TiO ${ }_{2}$ membrane were immersed at acid $\mathrm{pH}$ in dark or under irradiation. UV-visible absorbance spectra and photos of (d) s-PBC, (e) s-PBC-GO and (f) $s-\mathrm{PBC}^{-\mathrm{TiO}} \mathrm{O}_{2}$ membranes before and after the irradiation and the adsorption processes.

Their UV-vis absorbance spectra are reported in Fig. 14a (dark condition) and Fig. 14b (irradiation).

The membranes are able to remove the MO molecules both in dark and under irradiation, but the toxic by-products initially present in solutions A and B are neither adsorbed nor photocatalytically degraded. In summary, s-PBC-GO has the same degradation efficiency of s-PBC- $\mathrm{TiO}_{2}$ but it is safer, since it does not produce toxic by-products. Anyway, if the by-products are already present s-PBC-GO seems to be not able to remove them. Further investigation is needed in order to further clarify this aspect.

The degradation of methyl orange without the formation of toxic by-products under photocatalytic process was also observed in our precedent paper by using sulfonated $\mathrm{GO}^{.23}$ In order to compare the efficiency of degradation between s-PBC and Nafion, we have calculated the rate coefficient $k$ of MO degradation (Table 2) for the experiments in dark or under UVvisible irradiation of Fig. 11, using the relation $-\ln \left(C / C_{0}\right)=k \times$ $t$, where $C$ and $C_{0}$ are the residual and the initial MO concentrations, respectively, and $t$ is the time.

The larger sulfonation degree of s-PBC with respect to Nafion suggested by the IEC values is confirmed also by the MO adsorption experiments at $\mathrm{pH}=6$. Nafion can adsorb a little fraction of MO (residual concentration of $55 \%$ at the same illumination condition and initial MO concentrations ${ }^{25}$ ) while the adsorption in s-PBC is negligible after 3 hours due to the high electrostatic repulsion between s-PBC and MO. Also in this case we can also speculate that, not only the higher IEC value of 


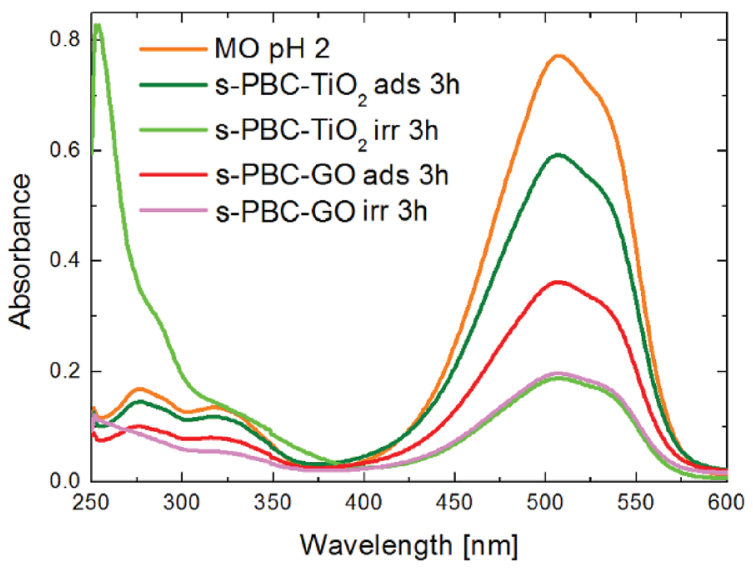

Fig. 13 UV-visible absorbance spectra of $\mathrm{MO}$ solution at $\mathrm{pH}=2$ in dark or after irradiation for three hours in the presence of s- $\mathrm{PBC}-\mathrm{TiO}_{2}$ (green and light green curves) and S-PBC-GO (red and magenta curves).

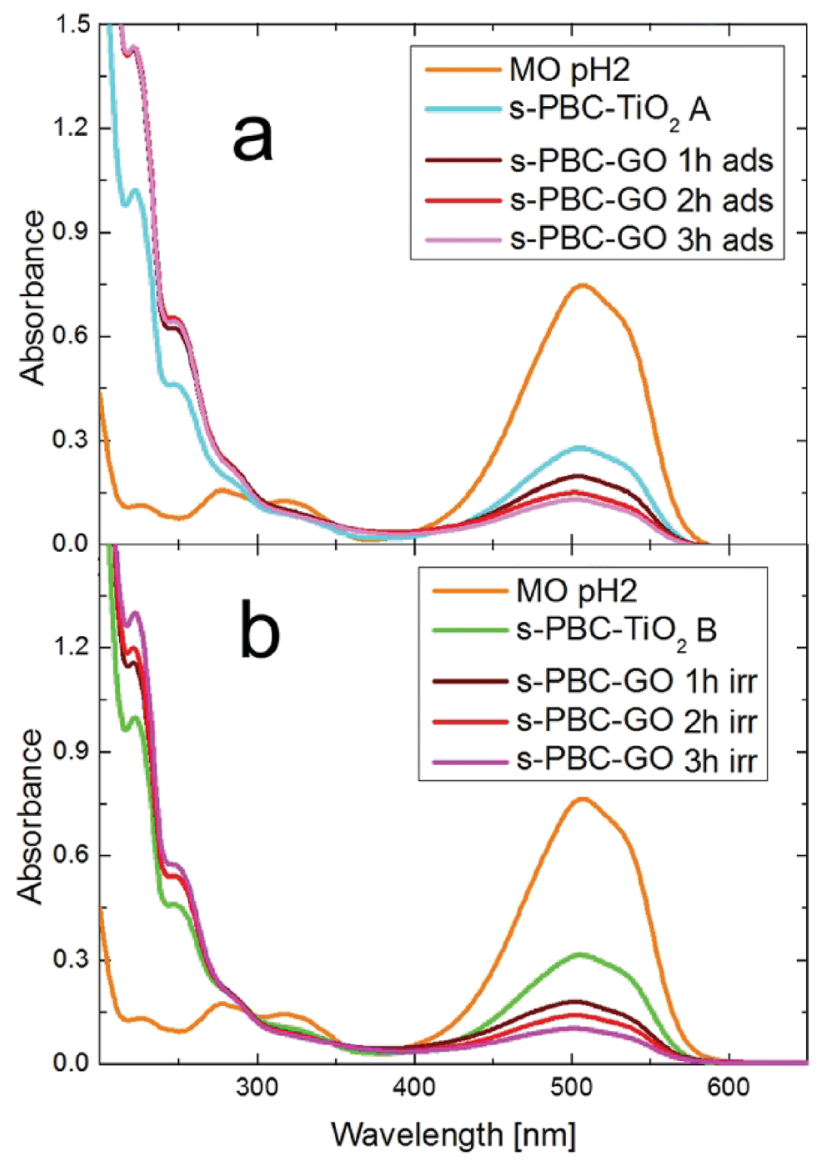

Fig. 14 UV-vis absorbance spectra of $\mathrm{MO}$ solution after irradiation in the presence of two different pieces of $\mathrm{s}-\mathrm{PBC}-\mathrm{TiO}_{2}$ membranes (named $\mathrm{A}$ and $\mathrm{B}$ ) and subsequently in contact with s-PBC-GO in dark (a) or under irradiation (b) for one, two and three hours.

s-PBC with respect to Nafion, but also their different structure plays an active role in the as shown different behaviour. The correlation of dyes adsorption/degradation with the structure of sulfonated polymers will be investigated in the future. For s-PBC
Table 2 Rate coefficient of degradation of $\mathrm{MO}$ at $\mathrm{pH}=2$ for the $\mathrm{s}-\mathrm{PBC}$ membranes and at $\mathrm{pH}=6$ for Nafion membranes, as reported in our previous work. $^{25}$

\begin{tabular}{|c|c|}
\hline Membrane & $k\left[\times 10^{-3} \min ^{-1}\right]$ \\
\hline s-PBC ads & $1.6 \pm 0.3$ \\
\hline s-PBC irr & $2.1 \pm 0.3$ \\
\hline s-PBC-GO ads & $1.9 \pm 0.1$ \\
\hline s-PBC-GO irr & $6.4 \pm 0.4$ \\
\hline $\mathrm{s}-\mathrm{PBC}-\mathrm{TiO}_{2}$ ads & $3.6 \pm 0.1$ \\
\hline s-PBC-TiO ${ }_{2}$ irr & $6.3 \pm 0.1$ \\
\hline Nafion $\operatorname{irr}^{a}$ & $3.8 \pm 0.4$ \\
\hline Nafion-GO irr ${ }^{a}$ & $4.1 \pm 0.2$ \\
\hline Nafion-TiO ${ }_{2}$ irr $^{a}$ & $6.7 \pm 0.2$ \\
\hline
\end{tabular}

composites, we lower the $\mathrm{pH}$ of $\mathrm{MO}$ solution $(\mathrm{pH}=2)$, favouring electrostatic interactions between protonated $\mathrm{MO}$ and negative sulfonilic groups in order to obtain similar or better rate coefficients than for Nafion nanocomposite membranes. The s-PBC materials show comparable activity with Nafion nanocomposites, so we propose them as an alternative to Nafion considering also that the preparation methodology of sulfonated pentablock copolymers is cheaper and safer than Nafion membranes.

Table 2 also shows that the irradiation increases the degradation rate for all s-PBC materials. Furthermore, the addition of nanofillers in the Nafion or s-PBC polymers increases the kinetic constant of degradation more significantly for s-PBC than for Nafion.

Furthermore, we have tested the possibility to regenerate the membranes and evaluate if they can be used more times without reducing their dye removal efficiency. The regeneration process has been described in the Experimental section (membrane preparation paragraph). Fig. 15 reports MO residual concentration achieved under irradiation for three consecutive uses of the composites, alternated with regeneration processes. The s-PBC-GO composite shows stability in the performance, while s-PBC- $-\mathrm{TiO}_{2}$ even increases in the second cycle and then

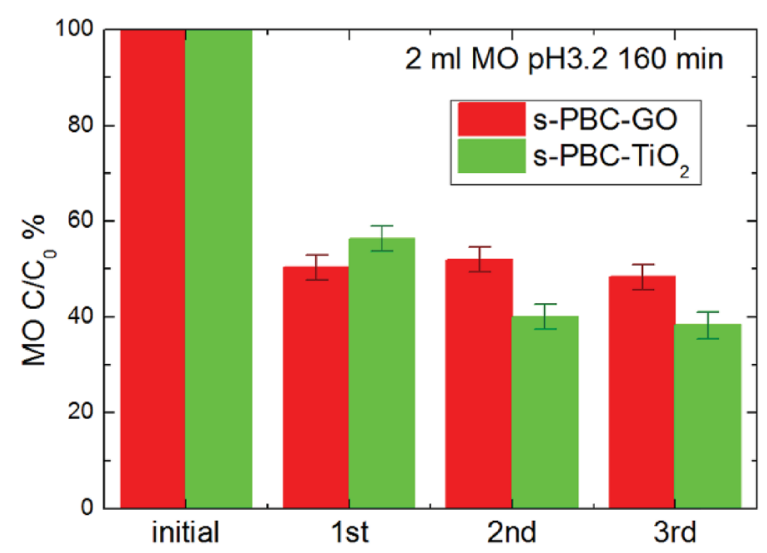

Fig. $15 \mathrm{MO}$ residual concentration versus three consecutive 3 hours irradiation processes, using the same pieces of s-PBC-GO (red bars) or s-PBC- $\mathrm{TiO}_{2}$ (green bars) membranes. 
remains stable. This confirms the possibility to recover easily the materials at the end of the processes, regenerating and reusing them for consecutive processes. As already highlighted in our previous works, ${ }^{21,23}$ this is the main advantage of using nanocomposite polymeric membranes instead of nanomaterials directly dispersed as powders in water.

\section{Conclusions}

Nanocomposite s-PBC membranes were prepared by dispersing GO and $\mathrm{TiO}_{2}$ in the polymeric solutions using DMF as solvent. The as-synthesized membranes are homogeneous, as confirmed by morphological and chemical characterization. In particular, s-PBC-GO shows a wrinkled and spongy structure, that, combined with the hydrophilic character of GO, is responsible of the enhanced water uptake; $\mathrm{s}-\mathrm{PBC}-\mathrm{TiO}_{2}$ shows the presence of titania agglomerates. TGA, XRD and Raman characterizations confirmed a different chemical interaction of the two nanomaterials within the polymer. In particular, titanium dioxide seems to interact mainly with sulfonilic groups and its dispersion inside the polymer generates a destabilizing effect. On the contrary, the dispersion of GO flakes increases the thermal stability of the polymer itself.

We have compared the dye degradation activity of the nanocomposite membranes with the filler-free membranes. All the materials are able to remove more than the $90 \%$ of the initial MB concentration either in dark or under irradiation. MB adsorption on the membranes is favoured by the electrostatic interactions with the negatively charged sulfonilic groups, and the dye is removed immediately (few minutes), without forming precipitates. For all the membranes the amount of monomers and dimers decrease with time, obtaining the same final concentration for both adsorption and irradiation processes. In addition, the introduction of fillers in s-PBC accelerates the MB monomer and dimer adsorption rate while higher degree aggregates are quickly formed in the first minutes; moreover, in the case of s-PBC- $\mathrm{TiO}_{2}$ and s-PBC-GO, the irradiation is more effective in the removal/degradation of higher aggregates with respect to the pure polymer. Anyway, in the absence of fillers, the s-PBC polymer is more efficient than Nafion in the removal of MB. This can be explained by the larger IEC and water uptake values of SPBC.

The same polymer and its composites are not able to adsorb MO within 24 hours of contact with dye solutions, due to electrostatic repulsion between the dye molecules and the sulfonilic groups. In acidic $\mathrm{pH}$ conditions, the membranes are able to adsorb protonated MO molecules. The MO degradation ability is increased under irradiation for all the materials by a factor of $50 \%$ for the composite with $\mathrm{TiO}_{2}$ and of $30 \%$ for the composite with GO, with respect to MO removal by adsorption. Finally, these two composites show the same degradation efficiency although the degradation occurs by different mechanisms.

Aromatic intermediate compounds are observed only after irradiation in the presence of s-PBC- $\mathrm{TiO}_{2}$ and not in the case of $\mathrm{s}-\mathrm{PBC}-\mathrm{GO}$, suggesting that for the latter composite membrane MO is removed by an adsorption process enhanced by irradiation. Therefore, MO dye removal from water is achieved in a safer way by a s-PBC-GO membrane instead of a s-PBC- $-\mathrm{TiO}_{2}$ membrane. The possibility to regenerate easily the materials at the end of the processes and reuse them for consecutive processes, has also been demonstrated.

In conclusion, we have shown an easy and low cost procedure for the preparation of reusable sulfonated pentablock copolymer nanocomposites, proposed as an alternative to Nafion, with promising ability in water purification application as adsorbent or photocatalytic material.

\section{Conflicts of interest}

There are no conflicts to declare.

\section{Acknowledgements}

The authors wish to thank G. Indelli (Consorzio Catania Ricerche) for technical support. The author S. F. acknowledges L. D'Urso for initial support in the Raman spectroscopy training. Kraton Polymers LLC is acknowledged for supplying the Nexar ${ }^{\mathrm{TM}}$ polymer. The author D. D. acknowledges the HORIZON 2020-JTI-FCH-2016-1 European Project "PECSYS" no. 735218 .

\section{References}

1 M. A. Hickner, C. H. Fujimoto and C. J. Cornelius, Transport in Sulfonated Poly(phenylene)s: Proton Conductivity, Permeability, and the State of Water, Polymer, 2006, 47(11), 4238-4244.

2 J. Ahn, H. Lee, T.-H. Yang, C.-S. Kim and B. Bae, Synthesis and Characterization of Multiblock Sulfonated Poly(arylene Ether Sulfone) Membranes with Different Hydrophilic Moieties for Application in Polymer Electrolyte Membrane Fuel Cell, J. Polym. Sci., Part A: Polym. Chem., 2014, 52, 2947-2957.

3 A. Sivasankaran, D. Sangeetha and Y. H. Ahn, Nanocomposite Membranes Based on Sulfonated Polystyrene Ethylene Butylene Polystyrene (SSEBS) and Sulfonated $\mathrm{SiO}_{2}$ for Microbial Fuel Cell Application, Chem. Eng. J., 2016, 289, 442-451.

4 A. S. H. Makhlouf and M. Hosseini, Industrial Applications for Intelligent Polymers and Coatings, ed. M. Hosseini and A. S. H. Makhlouf, Springer International Publishing, 2016.

5 A. Khan, Inamuddin, R. K. Jain and M. Naushad, Fabrication of a Silver Nano Powder Embedded Kraton Polymer Actuator and Its Characterization, RSC Adv., 2015, 5(111), 9156491573.

6 L. F. Greenlee, D. F. Lawler, B. D. Freeman, B. Marrot and P. Moulin, Reverse Osmosis Desalination: Water Sources, Technology, and Today's Challenges, Water Res., 2009, 43(9), 2317-2348.

7 H. B. Park, B. D. Freeman, Z. B. Zhang, M. Sankir and J. E. McGrath, Highly Chlorine-Tolerant Polymers for Desalination, Angew. Chem., Int. Ed., 2008, 47(32), 60196024 . 
8 R. W. Baker, Membrane Technology and Applications, John Wiley \& Sons LTD, 2nd edn, May 312004.

9 S. P. Nunes, Block Copolymer Membranes for Aqueous Solution Applications, Macromolecules, 2016, 49(8), 29052916.

10 G. M. Geise, B. D. Freeman and D. R. Paul, Characterization of a Sulfonated Pentablock Copolymer for Desalination Applications, Polymer, 2010, 51(24), 5815-5822.

11 G. M. Geise, C. L. Willis, C. M. Doherty, A. J. Hill, T. J. Bastow, J. Ford, K. I. Winey, B. D. Freeman and D. R. Paul, Characterization of Aluminum-Neutralized Sulfonated Styrenic Pentablock Copolymer Films, Ind. Eng. Chem. Res., 2013, 52(3), 1056-1068.

12 J. H. Choi, C. L. Willis and K. I. Winey, Effects of Neutralization with $\mathrm{Et}_{3} \mathrm{Al}$ on Structure and Properties in Sulfonated Styrenic Pentablock Copolymers, J. Membr. Sci., 2013, 428, 516-522.

13 J. H. Choi, C. L. Willis and K. I. Winey, Structure-Property Relationship in Sulfonated Pentablock Copolymers, J. Membr. Sci., 2012, 394-395, 169-174.

14 K. Fischer, M. Grimm, J. Meyers, C. Dietrich, R. Glaser and A. Schulze, Photoactive Microfiltration Membranes via Directed Synthesis of $\mathrm{TiO}_{2}$ Nanoparticles on the Polymer Surface for Removal of Drugs from Water, J. Membr. Sci., 2015, 478, 49-57.

15 H. Song, J. Shao, J. Wang and X. Zhong, The Removal of Natural Organic Matter with $\mathrm{LiCl}_{-\mathrm{TiO}}$-Doped PVDF Membranes by Integration of Ultrafiltration with Photocatalysis, Desalination, 2014, 344, 412-421.

16 K. Hashimoto, H. Irie and A. Fujishima, A Historical Overview and Future Prospects, AAPPS Bull., 2007, 17(6), 12-28.

17 D. C. Hurum, A. G. Agrios, K. A. Gray, T. Rajh and M. C. Thurnauer, Explaining the Enhanced Photocatalytic Activity of Degussa P25 Mixed-Phase $\mathrm{TiO}_{2}$ Using EPR, J. Phys. Chem. B, 2003, 107(19), 4545-4549.

18 N. Zhang, Y. Zhang and Y.-J. Xu, Recent Progress on Graphene-Based Photocatalysts: Current Status and Future Perspectives, Nanoscale, 2012, 4(19), 5792.

19 X. Xie, K. Kretschmer and G. Wang, Advances in GrapheneBased Semiconductor Photocatalysts for Solar Energy Conversion: Fundamentals and Materials Engineering, Nanoscale, 2015, 7, 13278-13292.

20 S. Filice, D. D'Angelo, S. F. Spanò, G. Compagnini, M. Sinatra, L. D'Urso, E. Fazio, V. Privitera and S. Scalese, Modification of Graphene Oxide and Graphene Oxide- $\mathrm{TiO}_{2}$ Solutions by Pulsed Laser Irradiation for Dye Removal from Water, Mater. Sci. Semicond. Process., 2016, 42, 50-53.

21 S. Scalese, I. Nicotera, D. D'Angelo, S. Filice, S. Libertino, C. Simari, K. Dimos and V. Privitera, Cationic and Anionic Azo-Dye Removal from Water by Sulfonated Graphene Oxide Nanosheets in Nafion Membranes, New J. Chem., 2016, 40(4), 3654-3663.

22 W. Gao, The Chemistry of Graphene Oxide, Graphene Oxide Reduct. Recipes, Spectrosc. Appl., 2015, pp. 61-95.

23 S. Filice, D. D'Angelo, S. Libertino, I. Nicotera, V. Kosma, V. Privitera and S. Scalese, Graphene Oxide and Titania
Hybrid Nafion Membranes for Efficient Removal of Methyl Orange Dye from Water, Carbon, 2015, 82(C), 489-499.

24 M. A. Buccheri, D. D'Angelo, S. Scalese, S. F. Spanò, S. Filice, E. Fazio, G. Compagnini, M. Zimbone, M. V. Brundo, R. Pecoraro, et al. Modification of Graphene Oxide by Laser Irradiation: A New Route to Enhance Antibacterial Activity, Nanotechnology, 2016, 27(24), 245704-245716.

25 D. D'Angelo, S. Filice, S. Libertino, V. Kosma, I. Nicotera, V. Privitera; S. Scalese, Photocatalytic Properties of Nafion Membranes Containing Graphene Oxide/Titania Nanocomposites, Proceedings of IEEE 9th Nanotechnology Materials and Devices Conference (NMDC), 2014, pp. 54-57.

26 Y. Fan and C. J. Cornelius, Raman Spectroscopic and Gas Transport Study of a Pentablock Ionomer Complexed with Metal Ions and Its Relationship to Physical Properties, $J$. Mater. Sci., 2013, 48(3), 1153-1161.

27 H. G. M. Edwards, D. R. Brown, J. A. Dale and S. Plant, Raman Spectroscopy of Sulfonated Polystyrene Resins, Vib. Spectrosc., 2000, 24(2), 213-224.

28 S. Sollinger and M. Diamantoglou, Determination of the Degree of Sulphonation of Sulphonated Poly(aryl Ether Sulphone), J. Raman Spectrosc., 1997, 28(10), 811-817.

$29 \mathrm{R}$. Buzzoni and S. Bordiga, Interaction of $\mathrm{H}_{2} \mathrm{O}$, $\mathrm{CH}_{3} \mathrm{OH},\left(\mathrm{CH}_{3}\right)_{2} \mathrm{O}, \mathrm{CH}_{3} \mathrm{CN}$, and Pyridine with the Superacid Perfluorosulfonic Membrane Nafion: An IR and Raman Study, J. Phys. Chem., 1995, 99(31), 11937-11951.

30 H. G. M. Edwards, D. R. Brown, J. R. Dale and S. Plant, Raman Spectroscopic Studies of Acid Dissociation in Sulfonated Polystyrene Resins, J. Mol. Struct., 2001, 595(13), 111-125.

31 L. Y. Yu, Z. L. Xu, H. M. Shen and H. Yang, Preparation and

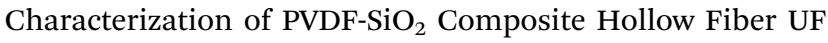
Membrane by Sol-Gel Method, J. Membr. Sci., 2009, 337(12), 257-265.

32 K. Thamaphat, P. Limsuwan and B. Ngotawornchai, Phase Characterization of $\mathrm{TiO}_{2}$ Powder by XRD and TEM $\backslash \mathrm{n}$, Nat. Sci., 2008, 42, 357-361.

33 P. Cui, J. Lee, E. Hwang and H. Lee, One-Pot Reduction of Graphene Oxide at Subzero Temperatures, Chem. Commun., 2011, 47(45), 12370.

34 J. H. Choi, A. Kota and K. I. Winey, Micellar Morphology in Sulfonated Pentablock Copolymer Solutions, Ind. Eng. Chem. Res., 2010, 49(23), 12093-12097.

$35 \mathrm{~J}$. Oakes and P. Gratton, Kinetic Investigations of the Oxidation of Methyl Orange and Substituted Arylazonaphthol Dyes by Peracids in Aqueous Solution, $J$. Chem. Soc. Perkin Trans. 2, 1998, 12, 2563-2568.

36 H. Trabelsi, M. Khadhraoui, O. Hentati and M. Ksibi, Titanium Dioxide Mediated Photo-Degradation of Methyl Orange by Ultraviolet Light, Toxicol. Environ. Chem., 2013, 95(4), 543-558.

37 C. Baiocchi, M. C. Brussino, E. Pramauro, A. B. Prevot, L. Palmisano and G. Marci, Characterization of Methyl Orange and Its Photocatalytic Degradation Products by HPLC/UV-VIS Diode Array and Atmospheric Pressure Ionization Quadrupole Ion Trap Mass Spectrometry, Int. J. Mass Spectrom., 2002, 214(2), 247-256. 